\title{
Hydrochars as Emerging Biofuels: Recent Advances and Application of Artificial Neural Networks for the Prediction of Heating Values
}

\author{
Ioannis O. Vardiambasis ${ }^{1}\left(\right.$, Theodoros N. Kapetanakis ${ }^{1}\left(\mathbb{D}\right.$, Christos $^{\text {D. Nikolopoulos }}{ }^{1}{ }^{(D}$, \\ Trinh Kieu Trang ${ }^{2}$, Toshiki Tsubota ${ }^{3}$, Ramazan Keyikoglu ${ }^{4}{ }^{\circledR}$, Alireza Khataee ${ }^{4,5}$ \\ and Dimitrios Kalderis ${ }^{1, *}$ \\ 1 Department of Electronic Engineering, Hellenic Mediterranean University, Chania, 73100 Crete, Greece; \\ ivardia@hmu.gr (I.O.V.); todokape@hmu.gr (T.N.K.); cnikolo@hmu.gr (C.D.N.) \\ 2 Applied Chemistry Course, Department of Engineering, Graduate School of Engineering, Kyushu Institute \\ of Technology, 1-1 Sensuicho, Tobata-ku, Kitakyushu 804-8550, Japan; trinhkieutrang_t57@hus.edu.vn \\ 3 Department of Applied Chemistry, Faculty of Engineering, Kyushu Institute of Technology, 1-1 Sensuicho, \\ Tobata-ku, Kitakyushu 804-8550, Japan; tsubota@che.kyutech.ac.jp \\ 4 Department of Environmental Engineering, Gebze Technical University, 41400 Gebze, Turkey; \\ ramazankeyikoglu@gmail.com (R.K.); a_khataee@tabrizu.ac.ir (A.K.) \\ 5 Research Laboratory of Advanced Water and Wastewater Treatment Processes, Department of Applied \\ Chemistry, Faculty of Chemistry, University of Tabriz, Tabriz 51666-16471, Iran \\ * Correspondence: kalderis@hmu.gr; Tel.: +30-28210-23017
}

Received: 19 August 2020; Accepted: 1 September 2020; Published: 3 September 2020

check for updates

\begin{abstract}
In this study, the growing scientific field of alternative biofuels was examined, with respect to hydrochars produced from renewable biomasses. Hydrochars are the solid products of hydrothermal carbonization (HTC) and their properties depend on the initial biomass and the temperature and duration of treatment. The basic (Scopus) and advanced (Citespace) analysis of literature showed that this is a dynamic research area, with several sub-fields of intense activity. The focus of researchers on sewage sludge and food waste as hydrochar precursors was highlighted and reviewed. It was established that hydrochars have improved behavior as fuels compared to these feedstocks. Food waste can be particularly useful in co-hydrothermal carbonization with ash-rich materials. In the case of sewage sludge, simultaneous P recovery from the HTC wastewater may add more value to the process. For both feedstocks, results from large-scale HTC are practically non-existent. Following the review, related data from the years 2014-2020 were retrieved and fitted into four different artificial neural networks (ANNs). Based on the elemental content, HTC temperature and time (as inputs), the higher heating values (HHVs) and yields (as outputs) could be successfully predicted, regardless of original biomass used for hydrochar production. $\mathrm{ANN}_{3}$ (based on $\mathrm{C}, \mathrm{O}, \mathrm{H}$ content, and HTC temperature) showed the optimum HHV predicting performance $\left(R^{2} 0.917\right.$, root mean square error 1.124), however, hydrochars' HHVs could also be satisfactorily predicted by the C content alone $\left(\mathrm{ANN}_{1}, \mathrm{R}^{2}\right.$ 0.897, root mean square error 1.289).
\end{abstract}

Keywords: hydrochar; hydrothermal carbonization; CiteSpace; scientometric analysis; artificial neural network; biofuels

\section{Introduction}

Subcritical water is hot water $\left(100-374^{\circ} \mathrm{C}\right)$ under enough pressure to maintain its liquid state. At these conditions, the dielectric constant of water is reduced, therefore it becomes a good solvent for non-polar substances. Throughout the 1980-1990s, this property was thoroughly exploited in subcritical 
water extraction and chromatography, for the isolation of natural products from environmental matrices and the replacement of hazardous organic solvents, respectively [1-5]. The tunable properties of subcritical water were later utilized to degrade organic contaminants in wastewater and soils. Several groups showed that recalcitrant contaminants, such as explosives and pesticides, can be degraded in-situ in relatively short times [6,7]. Furthermore, the addition of the environmentally-friendly hydrogen peroxide in subcritical water accelerates the degradation of contaminants due to the production of the highly reactive hydroxyl radicals $[8,9]$.

The term 'hydrothermal carbonization' (HTC) started appearing in the literature regularly in the early 2000s, to describe the upgrading or modification of materials and the synthesis of nanostructures in a subcritical water environment [10-12]. It still remains one of the main methods for the production of nanosized inorganic materials. Hydrothermal carbonization of biomass for the production of hydrochars for fuel purposes was first reported in 2010 [13]. In an effort to develop alternative fuels from sustainable sources, researchers focused on residual biomasses and agricultural by-products as hydrochar feedstocks. Since then, the number of papers that have studied hydrochar as biofuel has been steadily increasing. Depending on location and availability, a large number of biomasses has been investigated, from food waste and bamboo dust, to poultry litter and sugarcane bagasse. The main advantage - and difference from dry pyrolysis—is the method's potential to process high moisture biomasses. In all cases, the objectives were common: a competitive higher heating value (HHV) and a high solid yield. The mechanisms of biomass conversion to hydrochar have been established and reviewed in the literature [14-16]. Dehydration, decarboxylation, and decarbonylation reactions occur, the extent of which depends on processing conditions (mainly temperature, treatment time, and $\mathrm{pH}$ of feed water).

A few empirical models that provide the hydrochar mass yield (\%) and HHVs have been proposed $[17,18]$. However, these models are highly dependent on the biomass used and are therefore of limited applicability. Some others require an increased number of laboratory analyses for model input. The model developed by Conag et al. (2018) focused on sugarcane bagasse only and its charred derivatives. The suggested equation provided an adequate estimate of the HHV having a mean absolute error of $6.1 \%$ and a coefficient of determination (r2) of 0.91 [19]. Based on the severity factor $\left(\mathrm{R}_{\mathrm{o}}\right)$, polarity index (IP), and reactivity index (IR), Vallejo et al. (2020) developed a multilinear model for the prediction of the HHVs of hydrochars from various biomasses. However, the difficulty in using IP and IR is that earlier determination of $\mathrm{C}, \mathrm{H}, \mathrm{N}, \mathrm{S}$, hemicellulose, aqueous extractives, lignin, and ash content in the raw biomass is required [20]. Similarly, the regression model proposed by Akdeniz et al. (2020) required a significant number of time-consuming laboratory analyses as input data [21]. Furthermore, due to the complexity of lignocellulosic biomass even a small change in the experimental conditions (e.g., such as moisture content) may result in considerably different yields and/or HHVs. Additionally, different types of hydrothermal carbonization reactors have different heat transfer values, which affect the reaction rates and subsequently the composition of the final solid product. To date, an accurate and generic model to correlate HHVs to the very basic hydrochar properties, regardless of initial feedstock, moisture content, and reactor size/type, is missing [18].

Artificial intelligence (AI) is a wide area of rapid growth with a large number of applications including but not limited to telecommunications, medical diagnosis, healthcare, and robotics [22,23]. A powerful section of AI is the Artificial Neural Networks (ANNs), the function of which is inspired by the biological central nervous system. In general, ANNs can be treated as a computational method attempting to simulate the complex functions of the human brain. ANNs, and in particular multilayer perception ANNs (MLP-ANNs) with at least 2 hidden layers, can theoretically approximate any nonlinear function between their input and output data and may be considered as universal approximators. The fundamental building block of any ANN is the artificial neuron, which is a simplified form of the biological neuron. Every ANN can be modeled as a layered structure of neurons. The structure is composed of different layers, such as the input layer, a number of intermediate layers which are called hidden layers, and the output layer. The number of hidden layers varies and depends 
on the problem at hand. Each layer consists of a number of neurons, which through variable synaptic weights are connected to the neurons of the next layer. In addition to synaptic weights, the neurons consist of activation functions which limit the amplitude range of the neurons' outputs to [0,1] or $[-1,1]$. Something that is also important, in any neuron, is the role of the so-called bias, which is a constant value determining whether the neuron is activated or not. Synaptic weights and biases are free parameters that are calculated through a learning algorithm, in order to achieve the desired target outcome.

The use of ANNs in biomass exploitation studies is still at an early stage but the interest is growing. Bhange et al. (2017) developed a feed forward backpropagation ANN for the garden biomass pretreatment process from experimental data. The results of the developed ANN model were compared to those of the response surface methodology (RSM), achieving a mean square error (MSE) value equal to 0.121 [24]. Baruah et al. (2017) also modeled the same ANN architecture but for biomass gasification in fixed bed downdraft gasifiers. The corresponding $\mathrm{ANN}$ outputs for the concentration $\mathrm{CH}_{4} \%, \mathrm{CO} \%$, $\mathrm{CO}_{2} \%$, and $\mathrm{H}_{2} \%$ gas species were found to be in good agreement with the experimental data, attaining absolute fraction of variance $\left(R^{2}\right)$ values higher than 0.98 and root mean square error (RMSE) values less than 0.0915 [25]. Nasrudin et al. (2019) compared various training algorithms for modelling microwave pyrolysis of oil palm fiber for hydrogen and biochar production. Their inputs were the temperature, the microwave power, the nitrogen flow rate and their outputs were the weights of hydrogen and biochar. The best performance was achieved, as expected, by the Levenberg-Marquardt (LM) and the Bayesian Regulation (BR) training algorithms. The LM (BR) algorithm achieved RMSE values equal to $0.206(0.216)$ for hydrogen weight and 0.822 (0.886) for biochar weight prediction [26].

Several laboratory studies have investigated the effect of each HTC parameter on hydrochar properties and the behavior of the solid fuel during combustion/incineration. However, HTC is a complex process, largely feedstock-dependent, therefore, homogeneity and standardization of results are still lacking $[15,27]$. Very few works have developed mathematical models to correlate specific properties of hydrochars to their elemental content and HTC conditions [28]. Based on the above, the objectives of this work were the following: (1) to address the current areas of intense activity and trends of 'hydrochars as fuel' research by a visual scientometrics analysis performed by CiteSpace software, (2) review the recent advances in the areas (clusters) of highest activity, as indicated by the CiteSpace analysis and (3) perform an ANN statistical analysis to correlate the minimum number of fundamental hydrochar properties (regardless of original feedstock and moisture content) to the heating values reported in the published literature of 2014-2020.

The Java-based software CiteSpace was developed by Chaomei Chen in 2006 and it focuses on finding critical points in the development of a field or a domain, including identifying fast-growing topical areas, finding citation hotspots in the land of publications, decomposing a network (of publications, or authors, or geographical areas etc.) into clusters and automatically labeling clusters with the most frequent terms from citing articles [29,30]. The effectiveness of this approach has been shown in different fields, for example on climate change and tourism and recently in emerging trends of biochar research and applications [31,32].

\section{Data Acquisition, Methods, and Review of Recent Literature}

\subsection{Data Acquisition and Methods}

Scopus (2014-2020) was selected as the scientific database and the keywords were 'hydrochar' and 'fuel' (article title, abstract, keywords). A total of 270 papers were retrieved and categorized as follows: articles (225), conference papers (27), reviews (9), book chapters (5), and conference review (1). To gain an insight into the latest and most active research sub-topics, data acquisition was limited to the years 2018-2020. This yielded a total of 175 papers (8506 cited references), which were saved in ris format, as required by CiteSpace (version: 5.6.R5). The software can figure out the relationship between authors and the correlation between keywords as well as point out the emerging trends, hot 
topics (clusters) and gaps in the 'hydrochar as fuel' research field. In the generated network maps, each node represents one item (e.g., keyword or author), and the size of the node indicates the frequency of this item. The log-likelihood algorithm (LLR) was used as the calculation method to obtain the clustering results $[30,31]$.

With respect to the ANN analysis, Scopus publications from the years 2014-2020 were retrieved, using the same keywords as above. The required input data were the following: temperature $\left({ }^{\circ} \mathrm{C}\right)$ and time (hr) during hydrothermal carbonization, carbon, oxygen, and hydrogen content of hydrochars. The output parameters were the higher heating value (HHV, MJ/kg) and the \% solid yield (mass of produced hydrochar/mass of original biomass $\times 100$ ). These were the most commonly reported parameters in the related published literature. The reactor pressure during treatment was not included because it is known that during HTC, the effect of pressure on the products' composition and yield is minimal $[6,8,14]$. Other input (e.g., moisture of biomass) and output parameters (e.g. lower heating value) were considered but excluded due to the limited number of studies that have reported such data. From a total of 270 documents, 144 reported full sets of the required data therefore these studies were used for the ANN analysis. All simulations were performed in MATLAB environment, using the deep learning toolbox.

\subsection{Basic Characteristics of the Reviewed Publications (2014-2020)}

Figure 1 shows the number of publications and total citations each year for the period of 2014-2020. A steady increase can be observed for both, indicating an active and dynamic field of research. This research field is highly interdisciplinary, since biomass processing, hydrothermal carbonization and hydrochar characterization and application are based on distinctly different knowledge backgrounds. This is represented in the document distribution by subject area, with Energy, Environmental Science, and Chemical Engineering each hosting 29.6, 23.2, and $17.2 \%$ of the documents, respectively.

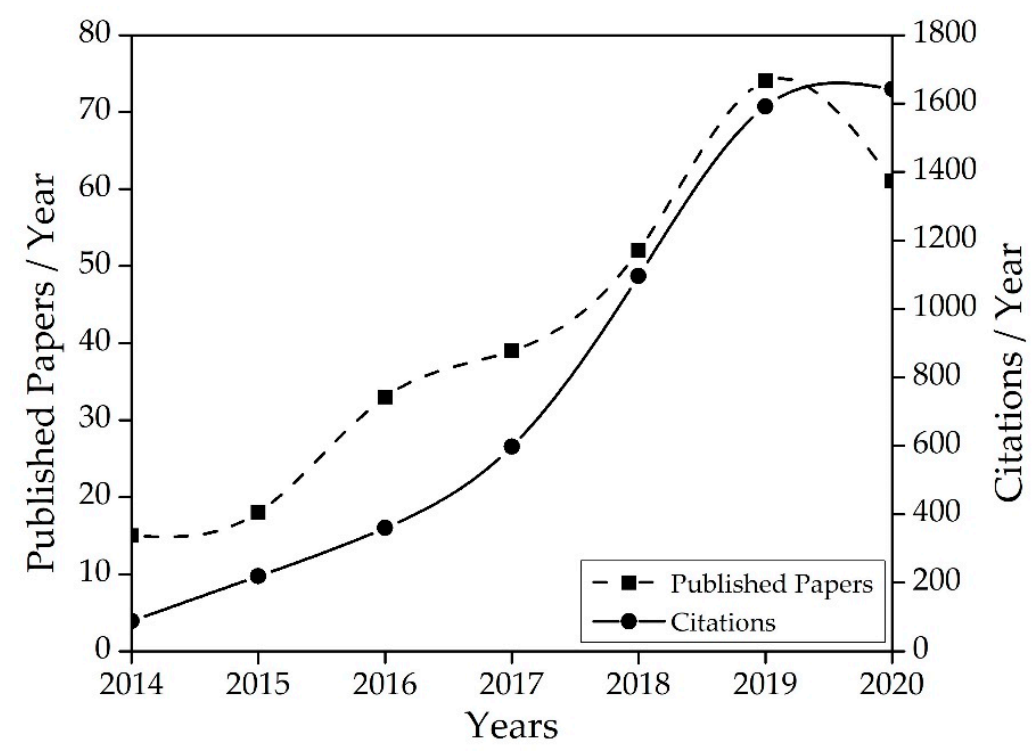

Figure 1. Citations and number of papers published using the keywords 'hydrochar' and 'fuel' for the period 2014-2020.

\subsection{CiteSpace Recent Scientometric Analysis (2018-2020)}

Table 1 shows the 8 sub-fields (clusters \#0-7) of intense activity determined for the period 2018-2020. Cluster labels are selected from noun phrases and index terms of citing articles (nodes) of each cluster. These terms are ranked by three different algorithms, thoroughly explained in the developer's publications [29,30]. The cluster with the lowest \#number corresponds to the sub-field with the highest number of published papers. Cluster \#0 (solid fuel hydrochar) corresponds to the fuel 
properties and combustion behavior of hydrochars, therefore is naturally where most papers have focused. Cluster \#1 (sludge-derived hydrochar), \#4 (food waste), and \#7 (corn stalk) point out the feedstock materials mostly used for fuel hydrochar production. These three clusters account for $>50 \%$ of the total published papers for the period 2018-2020. The compositional variety of each feedstock greatly adds to the complexity of hydrothermal carbonization and consequently leads to hydrochars with different physicochemical properties. In the following sections, the recent advances with respect to the valorization of sewage sludge and food waste for the production of hydrochar will be reviewed. Cluster \#2 (water source) highlights a very important aspect with respect to the techno-economic feasibility of hydrochar production at a large scale. Since water is an essential component during the process, the minimum required quantity will determine the need for potential recycling of HTC wastewater, thus offering an option to improve the overall efficiency. Clusters \#3 and 6 (and the papers within) focus on fundamental aspects of hydrothermal carbonization, already thoroughly reviewed in the literature. Cluster \#5 relates to the production of gases (greenhouse and others) during the combustion of hydrochars and will form part of a separate study in the future.

The average modularity value, the silhouette, and the most frequent common terms among the nodes of the same cluster can also be seen in Table 1. The modularity of a network of publications measures the extent to which the publications can be decomposed to multiple components or modules. If a network's modularity is close to 1.00 , then the network is clearly divided into thematically distinct clusters. In contrast, if modularity is below 0.30 , many between-cluster links could be expected. The value of 0.4122 indicates that clusters are rather closely related to each other and there is a certain number of common methodologies that are followed. It also highlights a research field with several gaps and unknown parameters, the effect of which has not been fully investigated. The silhouette value shows the homogeneity of a cluster and takes values between -1 and 1 . The higher the silhouette value, the more focused and consistent the papers of this cluster are, provided the clusters in comparison have similar sizes. The silhouette value for each and every cluster showed a significant degree of homogeneity, a result that is more meaningful for the clusters with the highest number of papers.

Table 1. Network modularity, cluster silhouette, the number of papers and the most frequently reported terms in the 2018-2020 clusters.

\begin{tabular}{cccc}
\hline Cluster & Network Modularity: 0.4122 & Number of Papers & $\begin{array}{c}\text { Most Frequently Reported Common } \\
\text { Terms Among the Papers of Each Cluster a }\end{array}$ \\
\hline 0 (solid fuel hydrochar) & 0.534 & 61 & $\begin{array}{c}\text { microwave, synthesis, green waste, fuel } \\
\text { properties }\end{array}$ \\
\hline $\begin{array}{c}1 \text { (sludge-derived } \\
\text { hydrochar) }\end{array}$ & 0.578 & 47 & $\begin{array}{c}\text { sustainable biomass fuel, sewage sludge, } \\
\text { pelletization technique }\end{array}$ \\
\hline 2 (water source) & 0.467 & 40 & $\begin{array}{c}\text { hydrochar properties, correlations, orange } \\
\text { peel waste, chemical constitution }\end{array}$ \\
\hline $\begin{array}{c}3 \text { (hydrothermal liquid } \\
\text { product) }\end{array}$ & 0.648 & 38 & $\begin{array}{c}\text { pyrolysis behaviour, pinewood sawdust, } \\
\text { maize straw }\end{array}$ \\
\hline 4 (food waste) & 0.59 & 27 & $\begin{array}{c}\text { comprehensive investigation, water source, } \\
\text { food waste, energy potential }\end{array}$ \\
\hline 5 (gas emission) & 0.639 & 15 & $\begin{array}{c}\text { solid biofuel production, effects, biogas } \\
\text { generation, co-hydrothermal gasification }\end{array}$ \\
\hline 6 (physicochemical \\
properties)
\end{tabular}

a The terms 'hydrothermal carbonization' and 'hydrochar' appear in all 8 clusters and were not added. 
The most commonly encountered keywords are presented in Table 2. Centrality is a relative term that quantifies the importance of a keyword within the research network. The keywords with high frequency and high centrality are generally considered as key nodes, indicating that they have a strong influence in the whole network for the given period [30]. All keywords of Table 2 are closely related to our research field and to each other, whereas expectedly 'temperature' showed the highest centrality value since it is the most influential parameter during hydrothermal carbonization $[14,15]$.

Table 2. The top 10 keywords related to 'hydrochar as fuel' research field for the years 2018-2020.

\begin{tabular}{cccc}
\hline Rank & Keyword & Frequency & Centrality \\
\hline 1 & Hydrothermal carbonization & 134 & 0.01 \\
2 & Carbonization & 132 & 0.01 \\
3 & Thermochemistry & 109 & 0.03 \\
4 & Hydrochar & 85 & 0.05 \\
5 & Fuel & 74 & 0.07 \\
6 & Carbon & 63 & 0.03 \\
7 & Biome & 57 & 0.02 \\
8 & Combustion & 54 & 0.07 \\
9 & Temperature & 46 & 0.12 \\
10 & Calorific value & 37 & 0.01 \\
\hline
\end{tabular}

\subsubsection{Valorization of Sewage Sludge for the Production of Fuel Hydrochar}

Sewage sludge management remains in the center of attention throughout the world. In the European Union, new directives and regulations focus on stabilization and valorization options instead of storage routes, such as landfilling or back-filling of mining areas [33-35]. Among the first to investigate the use of sewage sludge for hydrochar production, Zhao et al. (2014) realized that HTC has the advantages of volume reduction and energy densification of the original biomass. The authors concluded that temperature was the most influential parameter and suggested moderate HTC conditions $\left(200{ }^{\circ} \mathrm{C}, 30 \mathrm{~min}\right.$ treatment time) to produce hydrochar with an energy recovery rate of 50\% [36]. The results of Kim et al. (2014) largely agreed with these conclusions and further established the improvement in the fuel-related properties of hydrochars compared to the sewage sludge feedstock [37]. At $220^{\circ} \mathrm{C}$, a higher heating value of $18.3 \mathrm{MJ} / \mathrm{kg}$ was achieved, comparable to that of lignite coal and $12 \%$ higher than that of raw sewage sludge. Several researchers have confirmed the upgrading of fuel quality of sewage sludge through HTC, the categorization of hydrochar in the region of lignite (HHV $15-25 \mathrm{MJ} / \mathrm{kg}$ ) and the role of temperature as the main influential parameter [28,38-41]. However, most of these studies also showed gradual increases of ash content as the HTC temperature was raised, not a desirable attribute for fuel applications. It is therefore essential that the generally high ash content in sewage sludge (compared to lignocellulosic biomasses) is further investigated as it may affect the ash fusion temperature and slagging potential of hydrochar during combustion. The relative composition of ash determines to a large extent its behavior during combustion: potassium and sodium are transferred to the wastewater during HTC, whereas magnesium, phosphorus, and calcium mostly remain in the resultant solid fuel [42-45]. Therefore, if $\mathrm{Mg}$ and Ca minerals dominate the ash fraction in sewage sludge, they will be bound to the hydrochar matrix, thus increasing the possibility of causing slagging and fouling during combustion. The crucial role of ash and the transformation routes of sewage sludge building blocks (lipids, proteins, and polysaccharides) during HTC have been established and thoroughly discussed [46-48].

Recently, hydrothermal co-carbonization (co-HTC) has attracted attention in an effort to reduce the ash content, increase yields and generally improve the fuel properties of the final product. Ma et al. $(2019 a, 2019 b)$, examined the pyrolysis and gasification behavior of hydrochars prepared by co-HTC of sewage sludge and sawdust. Their thermodynamic and kinetics assessment indicated that co-HTC improved the pyrolysis reactivity and devolatilization performance of sewage sludge hydrochar [49]. Furthermore, the addition of sawdust increased the fixed carbon and calorific value of 
the produced hydrochars, whereas their gasification runs resulted in a maximized CO content at the optimum sawdust/sewage sludge ratio of 0.25 [50]. However, since both sewage sludge and sawdust were dried before HTC, water was added manually to maintain the hydrothermal conditions. To improve the water efficiency, partially dewatered sludge could be used and the moisture content of the mixture controlled by addition of various quantities of dry sawdust. The same co-HTC rationale was followed by Song et al. (2019) who mixed sewage sludge with lignite coal at 1:1 ratio and processed them hydrothermally at the temperature range of $120-300{ }^{\circ} \mathrm{C}$. The authors determined that the fuel properties of hydrochars were gradually enhanced as the temperature was raised and the optimum $\mathrm{HHV}$ of $16.93 \mathrm{MJ} / \mathrm{kg}$ was achieved at $240{ }^{\circ} \mathrm{C}$ and $30 \mathrm{~min}$ residence time [51]. In a similar approach, Wang et al. (2020) mixed dewatered sewage sludge with phenolic wastewater and produced hydrochars with increased HHV. This approach led to a substantial increase of hydrochar yield (1.83-31.11\%), a higher heating value (1.01-10.01\%) and a considerable decrease of ash content (1.39-25.68\%), depending on processing temperature and phenol concentration [52]. An advantage of this method was that no fresh water was used since the wet conditions were controlled by the wastewater addition. Promising results have also been obtained through the co-HTC of sewage sludge with microalgae [53], cow dung [54], and food waste $[55,56]$ in the temperature range of $200-230^{\circ} \mathrm{C}$ and $30 \mathrm{~min}$ residence time.

Worldwide, there is an increasing demand for plant nutrients such as phosphorus $(\mathrm{P})$. The increasing pressure on fossil $\mathrm{P}$ sources has directed efforts to recover $\mathrm{P}$ from renewable sources. Consequently, some groups have focused on obtaining two added-value products from HTC of sewage sludge, hydrochar as fuel, and P from the remaining wastewater. During HTC, some of P is solubilized, however most can be found in the solid product, due to the presence of $\mathrm{Fe}, \mathrm{Mg}$ and $\mathrm{Ca}$ ions which promote $\mathrm{P}$ precipitation as $-\mathrm{PO}_{4}{ }^{3-}$ on the hydrochar surface $[48,57,58]$. Recently, Becker at al. (2019) developed a method to remove P from hydrochars and precipitate it as struvite [59]. After an acid-leaching step, struvite was precipitated at $\mathrm{pH} 9$ by the ammonium-rich HTC wastewater. At the same time, their hydrochar had a HHV of $13.7 \mathrm{MJ} / \mathrm{kg}$ (HTC temperature $220^{\circ} \mathrm{C}$ ), highlighting that with the necessary fine-tuning, it is possible to produce two high added-value products from sewage sludge. Noticeably, the joint strategy of fuel hydrochars production and P reclamation has also received attention for high-P biomasses, other than sewage sludge [60].

Recently, Aragón-Briceño et al. (2020) achieved P solubilization in the range of $24-27 \%$ regardless of initial solids loading (HTC temperature $250{ }^{\circ} \mathrm{C}$, residence time $30 \mathrm{~min}$ ) [61]. Interestingly, the HHVs of their hydrochars were also rather independent of solid sludge loading, ranging from 15.4-16.5 MJ $/ \mathrm{kg}$. Their Aspen Plus analysis indicated a significant positive energy balance when process water and hydrochar were valorized as products. In another study, hydrothermal treatment of sewage sludge digestate at $180-240{ }^{\circ} \mathrm{C}$ did not result in high-rank hydrochars, due to the high ash content of the samples. However, when an acid-leaching step was added, lignite-like upgraded hydrochars were obtained and at the same time the acidic leachate was precipitated with the use of $\mathrm{CaO}$ to yield a total $\mathrm{P}$ content close to $42 \mathrm{mg} \mathrm{g}^{-1}$ [62]. The upgrading of hydrochar properties has also been confirmed when organic acids (e.g., oxalic acid) were used to extract and bind P [63]. It is worth noting that in these recent studies, HTC was performed with the natural water content of sewage sludge, without the addition of surplus water. Up to date, the study of Xu et al. (2020) is the only work that has evaluated the effect of aqueous phase recycling on the hydrochar properties, as part of a 'green' environmental engineering approach. The authors determined that the carbon content, nitrogen content and HHV of the hydrochars increased when the aqueous phase was recycled, leading to upgraded hydrochars and improved water use efficiency [64].

As indicated by Citespace, the greenhouse gases (GHGs) emission during the combustion of hydrochars is also an active research topic. The work of Wang et al. (2019) provided a comprehensive insight into the $\mathrm{SO}_{2}, \mathrm{NO}_{x}$, and $\mathrm{CO}$ emissions during the combustion of sewage sludge hydrochars at $1000{ }^{\circ} \mathrm{C}$. Similarly to earlier works, they obtained their optimum HHV at the HTC temperature of 230 ${ }^{\circ} \mathrm{C}$ [65]. They determined that $\mathrm{SO}_{2}$ emission was inversely correlated to HTC temperature, whereas $\mathrm{NO}_{\mathrm{x}}$ emission was almost constant up to the temperature of $260^{\circ} \mathrm{C}$. Although for most feedstocks HTC 
treatment results in an increased $\mathrm{N}$ content (due to the higher losses in organic substance), the opposite trend has been observed in sewage sludge hydrochars [66]. Still, the $\mathrm{N}$ content of sewage sludge hydrochars should always be monitored to minimize potential $\mathrm{NO}_{\mathrm{x}}$ emissions during the combustion phase. Towards this end, $\mathrm{Xu}$ et al. (2020) developed a layered double hydroxide (LDH) catalyst which they mixed with sewage sludge during HTC, in order to minimize the $\mathrm{N}$ content of the final product. The catalyst promoted the thermal decomposition of N-organic matter to $\mathrm{NH}_{4}{ }^{+}-\mathrm{N}$, which ended up in the HTC wastewater due to its high aqueous solubility [67].

\subsubsection{Valorization of Food Waste for the Production of Fuel Hydrochar}

Every year there are millions of tons of food waste disposed of in landfills without any form of valorization. As opposed to sewage sludge, food waste is very diverse in nature and heterogeneous in composition and production sources, thus rendering a unified management plan impractical at large-scale. It has been shown that HTC of food waste is a feasible alternative treatment method for the production of high quality fuel hydrochars, since no pretreatment is required and the moisture content is already high [68-70]. It has been generally established that hydrochars with C content and HHVs in the range of $45-93 \%$ and $15-30 \mathrm{MJ} / \mathrm{kg}$, respectively, can be obtained from food waste [71-73].

The role and transformation pathway of each basic food component (carbohydrates, proteins, lipids) has provided significant insights. Tradler et al. (2018) collected food waste from restaurants and separated them into vegetal, carbohydrate-rich, and animal-based food. After HTC treatment at $200{ }^{\circ} \mathrm{C}$ and 6 hours, they noticed that food high in proteins and fat resulted in lower hydrochar yields than feedstocks high in carbohydrates [74]. The HHV of the homogeneous, mixed food sample was in the order of $\sim 23 \mathrm{MJ} / \mathrm{kg}$. Later, Li et al. (2019) supported these findings and added that the carbohydrate content correlated positively to the fixed carbon content in hydrochar and enhanced the homogenization and thermal stability of the solid biofuel, resulting in a greater combustion performance [75].

Materials developed through pre-designed experimental processes in order to tackle a specific problem or deficiency are called engineered materials. Such an approach was implemented by Akarsu et al. (2019), who combined anaerobic digestion and HTC to convert vegetable and fruit waste to hydrochar with improved fuel properties. Indeed, anaerobic digestion followed by HTC at $250{ }^{\circ} \mathrm{C}$ and $30 \mathrm{~min}$ treatment time resulted in hydrochar with a HHV of $27.3 \mathrm{MJ} / \mathrm{kg}$ and $7.5 \%$ ash content [76]. Generally, ash and heavy metals do not appear to be an issue with food waste, although they are typically monitored in most HTC studies. Subsequently, steam gasification of the double-processed waste yielded $33 \mathrm{~mol} \mathrm{H}_{2} / \mathrm{kg}$ of hydrochar at $1050^{\circ} \mathrm{C}$. Nasir et al. (2020) converted spent brewery grains into hydrochars using different solvents during HTC. The group concluded that typical water-based HTC lead to hydrochar with the optimum fuel properties, however the use of methanol, ethanol and 2-propanol resulted in fundamentally different hydrochars, perhaps suitable for soil application or wastewater treatment processes [77]. It is worth noting that such an approach is not often reported in the literature and may be worth investigating further, as part of a multiple-product biorefinery concept.

Defective coffee beans have also been utilized for hydrochar production, with positive results. At $250{ }^{\circ} \mathrm{C}$ and $40 \mathrm{~min}$ treatment time, the resultant hydrochar had a C content, HHV and ash content of $68.3 \%, 29.1 \mathrm{MJ} / \mathrm{kg}$, and $0.07 \%$, respectively [78]. As a result, the combustion rate, reactivity and heat release were also improved compared to the respective coffee beans values. However, the low initial moisture content of the beans required the addition of water from an external source. Therefore, it would worth comparing the fuel properties and techno-economic efficiency of these hydrochars to biochars prepared through dry pyrolysis of the beans. Other food waste that have been successfully converted to fuel hydrochars include fruit residues, [79], orange peels [80], and cabbage processing waste [81]. HHVs in the range of 25-30 MJ/kg were reported in these studies.

Similarly to sewage sludge, food waste has been combined with other feedstocks in a co-HTC approach. Wang et al. (2018) combined food waste with wood sawdust to produce hydrochar fuel pellets with improved mechanical and storage characteristics. Hydrochar pellets (HTC $220^{\circ} \mathrm{C}$ ) with 
food waste ratios from 50 to $75 \%$ exhibited an increased tensile strength, decreased ignition temperature and maximum weight loss rate at a wider temperature range, indicating increased flammability [70]. However, contrary to sewage sludge, it is the food waste being used to upgrade the fuel properties of other materials.

The combination of food waste and low-rank coal appears to be gaining momentum. HHVs up to $31.4 \mathrm{MJ} / \mathrm{kg}$ were achieved when blended food waste and coal were mixed on a 1:1 basis and converted to hydrochar. The ash content of hydrochar obtained via the co-HTC at $300{ }^{\circ} \mathrm{C}$ was $53 \%$ less than the ash content of raw coal [82]. Mazumder et al. (2020a, 2020b) thoroughly investigated the co-HTC of food waste and bituminous coal waste, in an effort to reduce the ash, sulfur, and chloride content of the latter. Their optimum hydrochar (HHV of $23 \mathrm{MJ} / \mathrm{kg}$, sulfur content $1.4 \%$ ) was obtained at 230 ${ }^{\circ} \mathrm{C}$ and $30 \mathrm{~min}$ residence time [83]. Based on these optimum conditions, the authors made further progress by examining the technoeconomic feasibility of the co-HTC process and concluded that the raw material purchasing and transportation cost to be the most influential variable [84]. They noted that the mixture must have about $85 \%$ moisture to make sure the positive displacement pumps can pump the feedstock and they proposed to recycle the co-HTC process wastewater to maintain this level of moisture. The recycling of the HTC wastewater to reduce the water requirements of the process has also been supported by others [85].

\section{Results and Discussion}

\subsection{Statistical Analysis of Hydrochar Properties}

The statistical distribution of each one of the 7 hydrochar characteristics produced from biomass by pyrolysis is presented as a boxplot in Figure 2. In order to examine data dispersion, we used the interquartile range (IQR) and divided datasets into quartiles. Looking at each boxplot from top to bottom, five lines representing the maximum, the third quartile (Q3), the median, the first quartile (Q1), and the minimum of the corresponding data can be seen. The rectangular bullet represents the mean value, while the individual circle bullets are the outlier data values, which were not taken into account during the training process. In each plot, the useful data took values between Q1 - 1.5IQR and $\mathrm{Q} 3+1.5 \mathrm{IQR}$, where $\mathrm{IQR}=\mathrm{Q} 3-\mathrm{Q} 1$, while the outlier data took values below $\mathrm{Q} 1-1.5 \mathrm{IQR}$ or above $\mathrm{Q} 3+1.5 \mathrm{IQR}$.

With respect to the input parameters, the median (mean) temperature and time during hydrothermal carbonization were $219^{\circ} \mathrm{C}\left(227^{\circ} \mathrm{C}\right)$ and $1 \mathrm{hr}(3 \mathrm{hr})$, whereas the range of values was from 150 to $325^{\circ} \mathrm{C}$ (Figure 2a), and from 0.01 to $4 \mathrm{hr}$ (Figure 2b), respectively. Moreover, the median (mean) value of the carbon, the oxygen and the hydrogen content of hydrochars was $53 \%$ $(52 \%), 28 \%(29 \%)$, and $5.7 \%(5.6 \%)$, while their values varied from 23 to $82 \%$ (Figure $2 \mathrm{c}$ ), from 0.7 to $62 \%$ (Figure 2d), and from 3 to $9 \%$ (Figure 2e), respectively. On the other hand, for the output parameters, the median (mean) of the higher heating value and the \% solid yield was $22 \mathrm{MJ} / \mathrm{Kg}(22.1$ $\mathrm{MJ} / \mathrm{Kg}$ ) and $59 \%(58 \%$ ), while their values were in the range of $9-36 \mathrm{MJ} / \mathrm{Kg}$ (Figure $2 \mathrm{f}$ ) and $6-100 \%$ (Figure 2g), respectively.

During data acquisition, it was revealed that the variety of original biomass materials used for the production of hydrochars was large (Table 3). In some cases, HTC time was more than $4 \mathrm{~h}$, the carbon content of the resultant hydrochars was less than $23 \%$, and the hydrogen content was less than $3 \%$ (Figure 2b,c,e, respectively). Therefore, HTC time, carbon, and hydrogen content present the most outlier values, which could be excluded during neural network training and testing, in order for the ANN models to cover a smaller number of biomasses and achieve better performance. However, it was decided not to sacrifice collected data diversity and be as inclusive as possible in terms of original biomasses as this was one of the strategic objectives of this study. Inevitably, this would cost the accuracy of our ANN models, causing them difficulties in making predictions with absolute accuracy. 


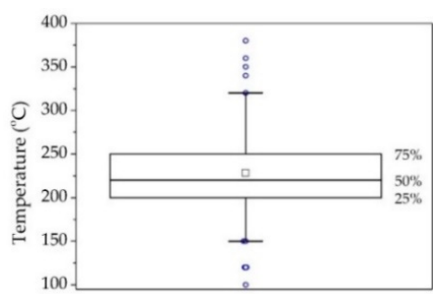

(a)

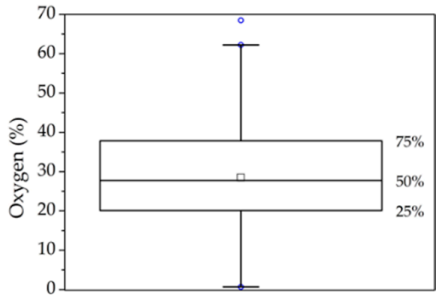

(d)

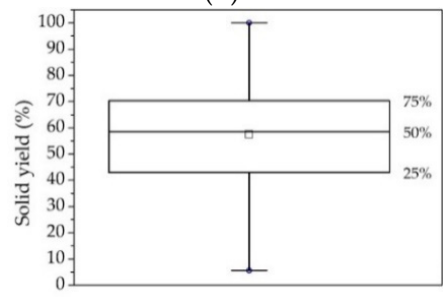

(g)

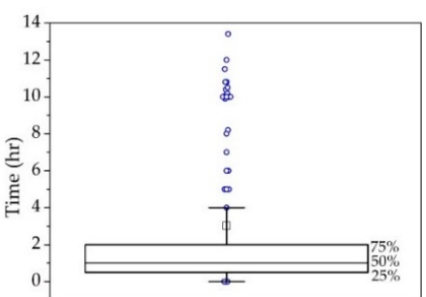

(b)

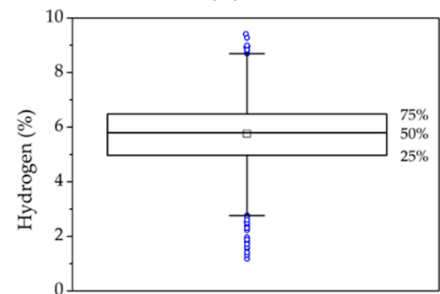

(e)

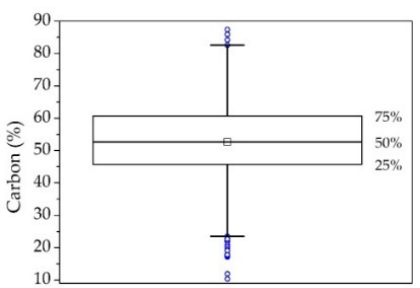

(c)

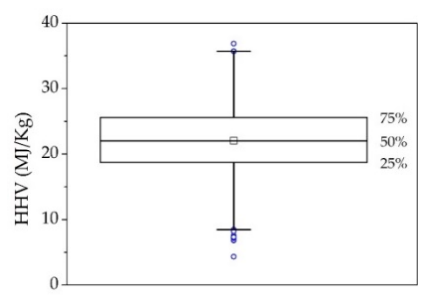

(f)

Figure 2. Boxplots of the values of (a) temperature, (b) time, (c) carbon, (d) oxygen, (e) hydrogen, (f) $\mathrm{HHV}$, and (g) solid yield, related to hydrochar composition.

Table 3. Biomasses used for the production of fuel hydrochar and included in data acquisition for the development of the artificial neural networks (ANN) models.

\begin{tabular}{cc}
\hline Biomass & \% Appearance in the Related Literature (2014-2020) \\
\hline Sewage sludge & 21.4 \\
Food waste & 15 \\
Corn cob & 12.6 \\
Rice husk & 8.8 \\
Olive mill waste & 7.6 \\
Lower grades of coal & 7.6 \\
Coconut processing residues & 3.8 \\
Miscanthus & 3.8 \\
Banana residues & 3.8 \\
Sugarcane bagasse & $<2$ \\
Wood sawdust & $<2$ \\
Paper sludge & $<2$ \\
Cotton stalk & $<2$ \\
Eucalyptus leaves & $<2$ \\
Bamboo residues & $<2$ \\
Tobacco stalk & $<2$ \\
Orange peels & $<2$ \\
Grape pomace & $<2$ \\
Poultry litter & $<2$ \\
Oil palm empty fruit bunch & $<2$ \\
Organic fraction of municipal waste & $<2$ \\
\hline
\end{tabular}




\subsection{Correlation Patterns between Hydrochar Properties}

In order to determine the relationships between any two of the 7 hydrochar characteristics, the Pearson Correlation Coefficient (PCC) $r$ was evaluated, using Equation (1)

$$
r_{y z}=\frac{\sum_{i=1}^{N}\left(y_{i}-\bar{y}\right) \sum_{i=1}^{N}\left(z_{i}-\bar{z}\right)}{\sqrt{\sum_{i=1}^{N}\left(y_{i}-\bar{y}\right)^{2}} \sqrt{\sum_{i=1}^{N}\left(z_{i}-\bar{z}\right)^{2}}}
$$

where, $y$ and $z$ are two randomly selected variables to be examined for linear dependence (correlation), $\bar{y}$ and $\bar{z}$ are their means, and $y_{i}$ and $z_{i}$ are individual values of the variables' datasets, respectively.

Table 4 presents the $7 \times 7$ Pearson correlation matrix, revealing correlations, either positive or negative, when the corresponding significance level $p$ is less than 0.01 . Therefore, the higher heating value was found to be positively correlated with temperature $(p<0.01)$, carbon content $(p<0.01)$, and hydrogen content $(p<0.01)$, but negatively correlated with oxygen content $(p<0.01)$ and solid yield $(p$ $<0.01)$. Similarly, the carbon content was found to be positively correlated with temperature $(p<0.01)$, hydrogen content $(p<0.01)$, and higher heating value $(p<0.01)$, but negatively correlated with oxygen content $(p<0.01)$ and solid yield $(p<0.01)$.

The relation between any two hydrochar properties was denoted by the value of $r$ from Equation (1), with higher PCC values indicating closer relation. Thus, HHV was closely related to carbon content $(r=0.886)$ and to a lesser extent to oxygen content $(r=-0.411)$, hydrogen content $(r=0.345)$, and temperature $(r=0.321)$. The correlation to solid yield $(r=-0.164)$ and HTC time $(r=0.129)$ was minimal. Similarly, the carbon content showed a high correlation to HHV, temperature, hydrogen content, and oxygen content, but low correlation to solid yield and time.

In order to investigate these relations and determine the deeper relationship between HHV and its influencing factors, three different ANN models were developed: (1) the $\mathrm{ANN}_{1}$ to predict the HHV values when only the carbon content (the factor with the closer relation) is known, (2) the $\mathrm{ANN}_{2}$ to predict the HHV values when carbon, oxygen, hydrogen, temperature and time (factors with close or loose relation) are given as inputs, and (3) the $\mathrm{ANN}_{3}$ to predict the $\mathrm{HHV}$ values when carbon, oxygen, hydrogen, and temperature (only factors with close relation) are given as inputs. Moreover, in order to determine the deep relationship between the carbon content and its influencing factors, we also develop the $\mathrm{ANN}_{4}$ to predict the $\mathrm{C}$ content values when $\mathrm{HHV}$, temperature, hydrogen, and oxygen (only factors with close relation) are given as inputs. Keeping in mind the relations suggested by Table 4, we expect that $\mathrm{ANN}_{3}$ will yield the best $\mathrm{HHV}$ predictions.

Table 4. Pearson correlation matrix between hydrochar properties $(C I=99 \%)$.

\begin{tabular}{cccccccc}
\hline PCC & Temperature & Time & Carbon & Hydrogen & Oxygen & HHV & $\begin{array}{c}\text { Solid } \\
\text { Yield }\end{array}$ \\
\hline Temperature & 1.000 & -0.044 & $0.310^{*}$ & $-0.158^{*}$ & $-0.305^{*}$ & $0.321 *$ & $-0.299^{*}$ \\
Time & -0.044 & 1.000 & 0.132 & 0.123 & -0.030 & 0.129 & 0.021 \\
Carbon & $0.310^{*}$ & 0.132 & 1.000 & $0.286 *$ & $-0.284^{*}$ & $0.886^{*}$ & $-0.182^{*}$ \\
Hydrogen & $-0.158^{*}$ & 0.123 & $0.286^{*}$ & 1.000 & 0.074 & $0.345^{*}$ & -0.107 \\
Oxygen & $-0.305^{*}$ & -0.030 & $-0.284^{*}$ & 0.074 & 1.000 & $-0.411^{*}$ & $0.254^{*}$ \\
HHV & $0.321^{*}$ & 0.129 & $0.886^{*}$ & $0.345^{*}$ & $-0.411^{*}$ & 1.000 & $-0.164^{*}$ \\
Solid Yield & $-0.299^{*}$ & 0.021 & $-0.182 *$ & -0.107 & $0.254^{*}$ & $-0.164 *$ \\
\hline
\end{tabular}




\subsection{Artificial Neural Network Modeling}

The block diagrams of the ANN models applied in this paper are displayed in Figure 3. The multilayer perceptron (MLP) architecture [22,23,86,87], which is popular for similar applications according to the universal approximation theorem, was implemented for each ANN model of Figure 3.
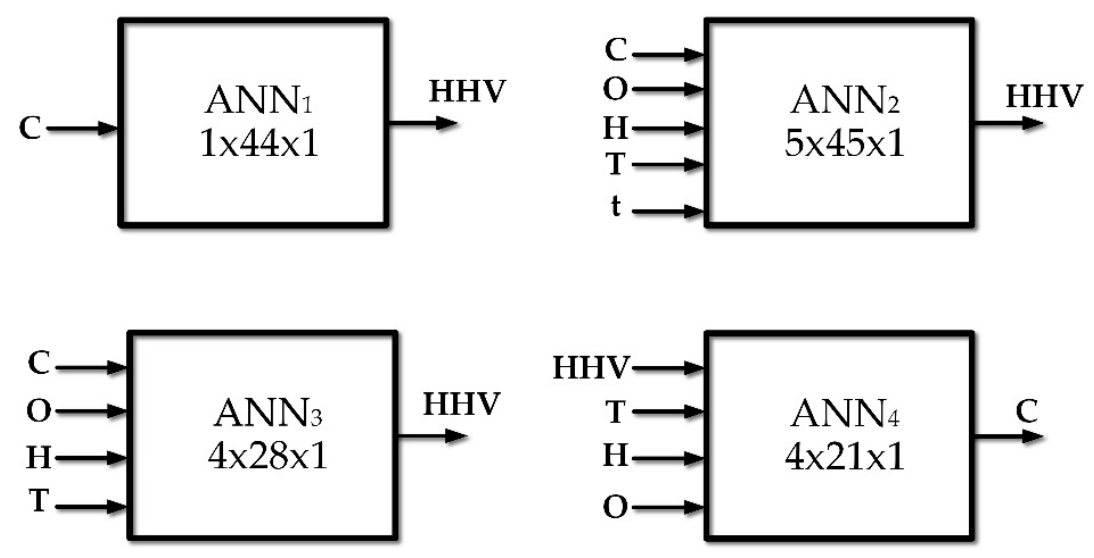

Figure 3. ANN models for hydrothermal carbonization. Each ANN box has the input hydrochar parameter(s) on the left, the output parameter on the right, and the number of neurons of the input, the hidden and the output layers inside.

The typical structure of an MLP ANN with three layers is shown in Figure S1 (Supplementary Materials). The number of neurons in each layer is denoted by $M_{n}, n=1,2, \ldots, N$. The index $n$ identifies the layers; $n=1$ refers to the first (input) layer, and $n=N$ to the last (output) layer. The vector $\mathbf{x}=\left\{x_{1}, x_{2}, \ldots, x_{M_{0}}\right\}$ denotes the input to ANN's first layer, where $M_{0}$ is the number of inputs. The vector $\mathbf{y}^{n}=\left\{y_{1}^{n}, y_{2}^{n}, \ldots, y_{M_{i}}^{n}\right\}$ represents the output of the $n$-th layer. The MLP ANN of Figure 3 has a sequential structure, as the output of the $n$-th layer is forwarded to the input of the $(n+1)$-th layer. Therefore, $\mathbf{y}^{n}=\Psi^{n}\left(\mathbf{y}^{n-1} \mathbf{w}^{n}+\mathbf{b}^{n}\right)$, where the activation function $\Psi^{n}$ is properly selected, the vector $\mathbf{b}^{n}$ contains the bias terms of the $n$-th layer, and the matrix $\mathbf{w}^{n}$ carries the adjustable synaptic weights $w_{i, j}^{n}$ (with $i=1,2, \ldots, M_{n-1}, j=1,2, \ldots, M_{n}$ ), the adjustment of which, is arranged by the appropriate training algorithm.

In order to solve the forward problem of predicting the HHVs of the hydrochars, or the quasi-inverse problem of determining the required $\mathrm{C}$ content of hydrochar to achieve a specific HHVs, the ANN models shown in Figure 3 had only one output and one, four or five hydrochar parameters as inputs. For the forward problem, $\mathrm{ANN}_{1}, \mathrm{ANN}_{2}$, and $\mathrm{ANN}_{3}$ had 1 output (HHV), and 1 (carbon), 5 (carbon, oxygen, hydrogen, temperature, and time), and 4 (carbon, oxygen, hydrogen, and temperature) inputs, respectively. For the quasi-inverse problem, $\mathrm{ANN}_{4}$ had 1 output (carbon) and 4 inputs (HHV, temperature, hydrogen, and oxygen).

\subsection{Data Preprocessing}

Before the training procedure, the hydrochar data were normalized into a predefined range, in order to avoid large values that may result in unstable neural networks with poor learning performance and consequently bad generalization. All hydrochar variables were normalized according to Equation (2) into the range $[-1,1]$ :

$$
x_{i}^{\prime}=\frac{\left(x_{b}-x_{a}\right)\left(x_{i}-x_{\min }\right)}{\left(x_{\max }-x_{\min }\right)}+x_{a}
$$

where, $x_{i}^{\prime}$ is the normalized value of sample $x_{i}, x_{b}=1, x_{a}=-1$, and $x_{\max }$ and $x_{\min }$ are the maximum and minimum values of $x_{i}$. 
After normalization, the data were divided into training, validation and testing distinct datasets, as $70 \%, 15 \%$, and $15 \%$ fractions of the whole data series, respectively. The training dataset was used during the learning process to train and fit the ANN model. The validation dataset was used to validate the ANN model during the hyperparameters' adjustments by the learning algorithm and to early stop the training algorithm in order to avoid overfitting. Finally, the testing dataset, which is an independent set of data kept unseen from the ANN model during training, was used to evaluate the performance and to test the quality of the model $[86,87]$.

The structure of all ANN models of Figure 3 follow the general block diagram of Figure S1 (Supplementary Materials), while the hyperbolic tangent sigmoid activation function was adopted and the Levenberg-Marquardt (LM) learning algorithm was selected in all cases. The learning process was repeated 33 times calculating its average performance, in order to ensure its stability and generalization capability [22]. Finally the number of neurons in the hidden layer was determined when the training Mean Relative Error (MRE), defined by Equation (3), was minimized

$$
M R E=\frac{1}{K} \sum_{k=1}^{K}\left(\left|\frac{p_{k}-e_{k}}{e_{k}}\right|\right)
$$

where, $e_{k}$ and $p_{k}$ stand for the $k$-th experimental and predicted values of the output hydrochar parameters, and $K$ is the multitude of values used for testing. Using the trial and error method, the number of hidden layer neurons was scanned for each of the four ANN models calculating MRE. Its values, varying between $0.04 \%$ (best case for $\mathrm{ANN}_{3}$ and $\mathrm{ANN}_{4}$ ) and $4.3 \%$ (worse case for $\mathrm{ANN}_{2}$ ), are depicted in Figure S2 (Supplementary Materials). Carefully selecting 44, 45, 28, and 21 neurons in the hidden layer of $\mathrm{ANN}_{1}, \mathrm{ANN}_{2}, \mathrm{ANN}_{3}$, and $\mathrm{ANN}_{4}$, respectively, an error of less than $2.1 \%$ was achieved in all cases. This is a satisfactory and well promising outcome for our ANN models.

\subsection{Performance of ANN Models}

When the ANN training and validation processes were completed, the four models implemented herein were tested for their quality and performance, using the testing datasets, which consisted of couples of the form $\left(C_{k}^{t e}, H H V_{k}^{t e}\right)$ for the $\mathrm{ANN}_{1}$, sextets of the form $\left(C_{k}^{t e}, O_{k}^{t e}, H_{k}^{t e}, T_{k}^{t e}, t_{k}^{t e}, H H V_{k}^{t e}\right)$ for the $\mathrm{ANN}_{2}$, quintets of the form $\left(C_{k}^{t e}, \mathrm{O}_{k}^{t e}, H_{k}^{t e}, T_{k}^{t e}, H H V_{k}^{t e}\right)$ for the $\mathrm{ANN}_{3}$, and quintets of the form $\left(H H V_{k}^{t e}, T_{k}^{t e}, H_{k}^{t e}, O_{k}^{t e}, C_{k}^{t e}\right)$ for the $\mathrm{ANN}_{4}$, where $k=1,2, \ldots, K$ and $C_{k}^{t e}, H H V_{k}^{t e}, O_{k}^{t e}$ and $H_{k}^{t e} T_{k}^{t e}$ and $t_{k}^{t e}$, the testing input values (or required outputs) of the hydrochar C content, HHVs, oxygen and hydrogen content, HTC temperature and duration, respectively. $K$ stands for the number of samples used for testing and has been set equal to 100, 65, 70 or 76 , for $\mathrm{ANN}_{1}, \mathrm{ANN}_{2}, \mathrm{ANN}_{3}$, and $\mathrm{ANN}_{4}$, respectively. The statistical measures calculated herein for the examination of the generalization and prediction ability of the proposed ANNs and the evaluation of the models' performance were the root mean squared error (RMSE) and the regression coefficient $\left(R^{2}\right)$, defined as follows:

$$
\begin{gathered}
\text { RMSE }=\sqrt{\frac{1}{K} \sum_{k=1}^{K}\left(p_{k}-e_{k}\right)^{2}} \\
R^{2}=1-\frac{\sum_{k=1}^{K}\left(p_{k}-e_{k}\right)^{2}}{\sum_{k=1}^{K}\left(p_{k}-\bar{e}\right)^{2}}
\end{gathered}
$$

where, $e_{k}$ is the $k$-th experimental value of the output biochar $\left(H H V_{k}^{t e}\right.$ for the $\mathrm{ANN}_{1}, \mathrm{ANN}_{2}, \mathrm{ANN}_{3}$ models, or $C_{k}^{t e}$ for the $\mathrm{ANN}_{4}$ model), $\bar{e}$ represents the average of the experimental output values, and 
$p_{k}$ is the $k$-th predicted value of the output biochar $\left(H H V_{k}^{p r}\right.$ for the $\mathrm{ANN}_{1}, \mathrm{ANN}_{2}, \mathrm{ANN}_{3}$ models, or $C_{k}^{p r}$ for the $\mathrm{ANN}_{4}$ model).

Comparisons of the predicted from the ANN models output hydrochar parameters with their corresponding measured HHVs or C contents are offered in Figure 4. The solid lines correspond to the experimental data deduced from the published literature, whereas the markers represent the predicted values of HHV or the carbon content by the model indicated in the inset. It is apparent that the proposed ANN models were able to predict both HHVs and C contents. Moreover, the performance of $\mathrm{ANN}_{1}$ and $\mathrm{ANN}_{4}$ seemed to be slightly better, especially for values of HHV lower than $20 \mathrm{MJ} / \mathrm{Kg}$ and $\mathrm{C}$ contents lower than $55 \%$, respectively. Still, the overall performance of all ANNs was of sufficient accuracy.

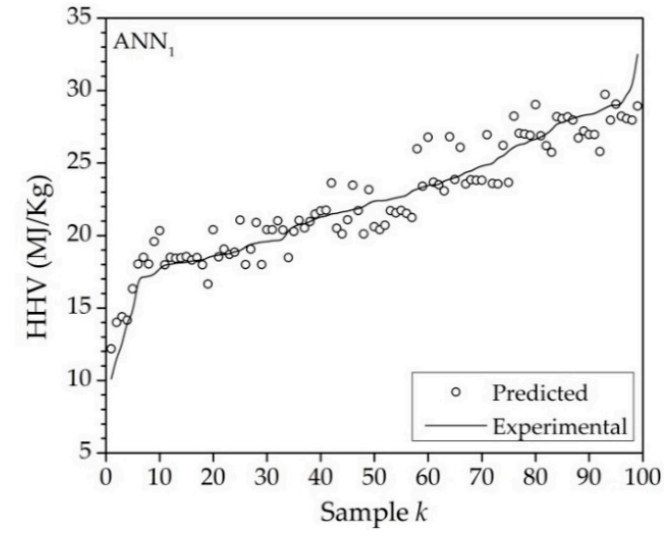

(a)

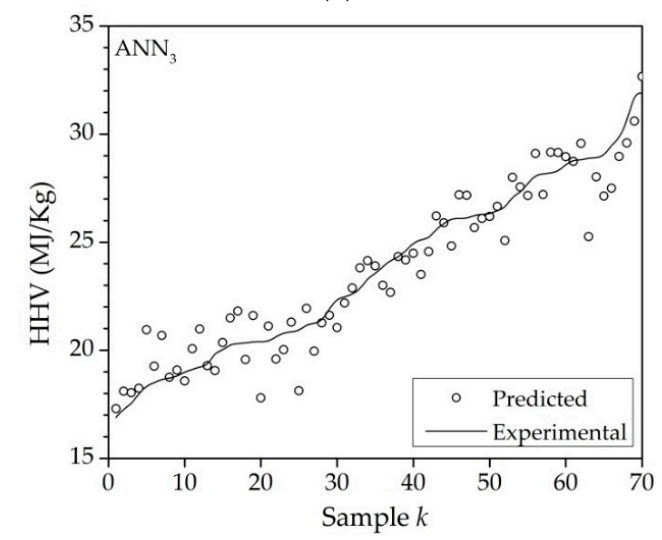

(c)

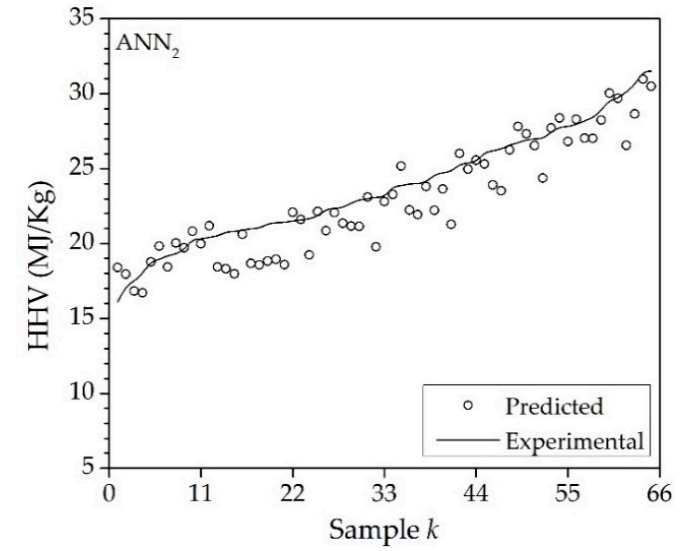

(b)

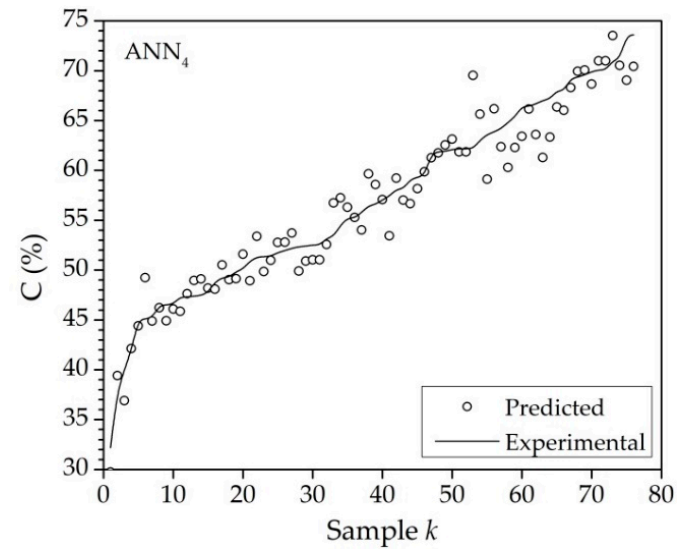

(d)

Figure 4. Experimental, $H H V_{k}^{t e}$ or $C_{k}^{t e}$, and predicted, $H H V_{k}^{p r}$ or $C_{k}^{p r}$ from (a) $\mathrm{ANN}_{1}$, (b) $\mathrm{ANN}_{2}$, (c) $\mathrm{ANN}_{3}$, and (d) $\mathrm{ANN}_{4}$ output biochar values.

Finally, the predicted outputs of the ANN models were plotted against their matching experimental values in Figure 5. While the overall RMSE and $\mathrm{R}^{2}$ values developed by our models were acceptable, the $\mathrm{ANN}_{3}$ (with $\mathrm{R}^{2}=0.917$ and $\mathrm{RMSE}=1.124$ ) appeared to perform better than $\mathrm{ANN}_{1}$ (with $\mathrm{R}^{2}=0.897$ and $\mathrm{RMSE}=1.289$ ) and $\mathrm{ANN}_{2}$ (with $\mathrm{R}^{2}=0.879$ and $\left.\mathrm{RMSE}=1.340\right)$. The prediction ability of $\mathrm{ANN}_{3}$, in which the RMSE is lower by $13 \%$ and $16 \%$ than that of $\mathrm{ANN}_{1}$ and $\mathrm{ANN}_{2}$, was superior because $\mathrm{HHVs}$ were predicted having as inputs all the closely-correlated hydrochar parameters $(\mathrm{C}, \mathrm{O}, \mathrm{H}$, and temperature), in contrast to $\mathrm{ANN}_{1}$ and $\mathrm{ANN}_{2}$. Moreover, as shown in Figure $5 \mathrm{~d}, \mathrm{ANN}_{4}$ achieved a very good performance with a high $\mathrm{R}^{2}=0.943$ despite the mediocre $\mathrm{RMSE}=2.188$. 


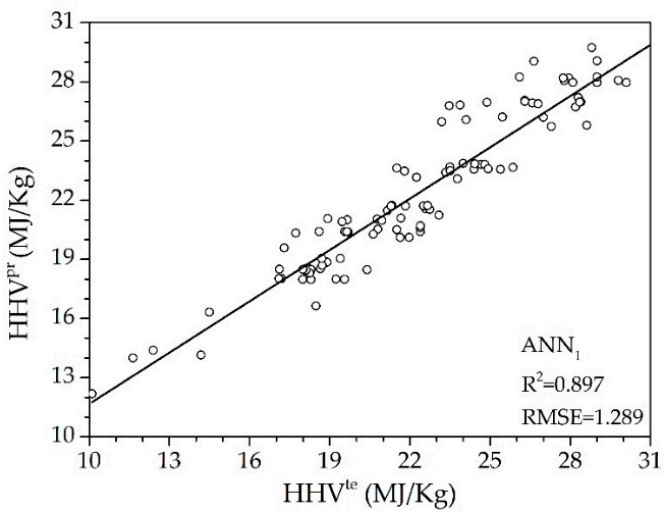

(a)

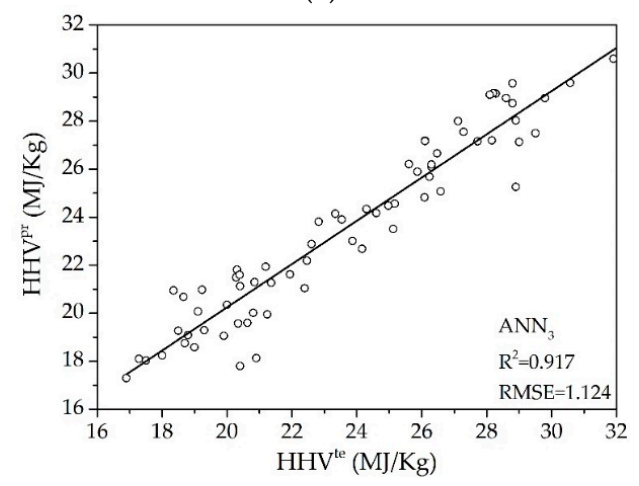

(c)

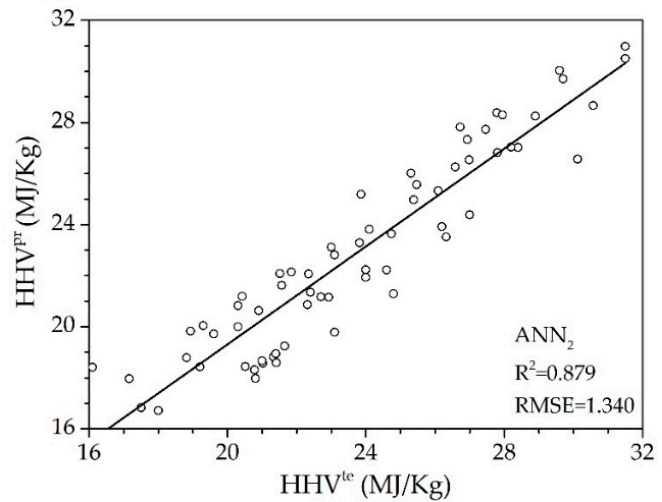

(b)

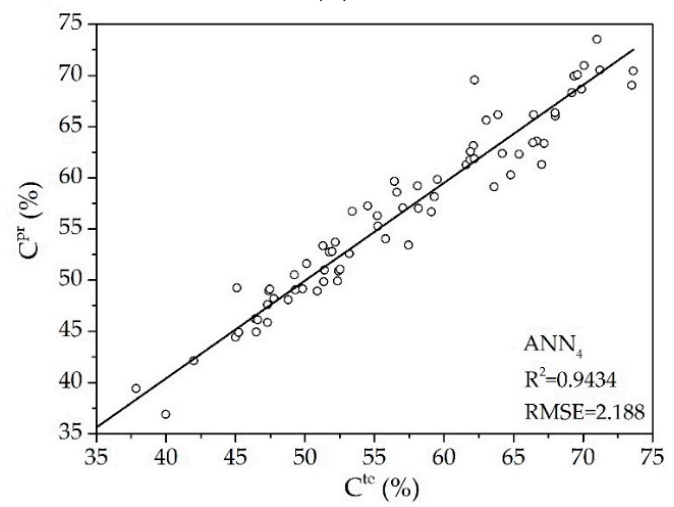

(d)

Figure 5. Regression analysis of predicted and experimental data (a) for higher heating values (HHV) using $\mathrm{ANN}_{1}$, (b) for $\mathrm{HHV}$ using $\mathrm{ANN}_{2}$, (c) for $\mathrm{HHV}$ using $\mathrm{ANN}_{3}$, and (d) for carbon using $\mathrm{ANN}_{4}$.

It is evident from Figure $4 \mathrm{a}-\mathrm{c}$ or Figure $5 \mathrm{a}-\mathrm{c}$ that our ANN models managed to predict, even though not so accurately in some cases, the HHVs of fuel hydrochars. Minor performance limitations may be attributed to: (1) the heterogeneity of the experimental data, used for training, validation, and testing of our ANN models, as they were gathered from a vast number of literature papers related to a wide range of biomass materials and experimental conditions, (2) the inevitable existence of plethora of multivalued data, as several different published works studying HTC of numerous biomass materials with discrete biochar characteristics (used as input data $\mathrm{C}, \mathrm{O}, \mathrm{H}, \mathrm{T}, \mathrm{t}$ ) resulted in very close or even the same HHVs (used as output data HHV), (3) the non-removal of the outlier collected data values, in order for our ANN models to take into account data from as many biomasses as possible, and (4) the dimensionality of input variables, since model performance is improved only when important input variables are used.

\section{Conclusions}

Conclusively, there is considerable potential in the valorization/co-valorization of various biomasses for the production of hydrochars with improved fuel properties. Sewage sludge and food waste are the main precursor materials at the moment. Processing temperatures and times in the range of $200-230{ }^{\circ} \mathrm{C}$ and $30-60 \mathrm{~min}$ appear to be the optimum in many cases. Recovery of $\mathrm{P}$ through acid-leaching further improves the feasibility of the process and results in hydrochars with lower ash contents. As has always been the case with sewage sludge, monitoring of the fate of heavy metals should always be performed. A significant research gap is the utilization and recycling of various real wastewaters (as feed waters in HTC) on hydrochar properties and subsequent impact on combustion behavior and GHG emission. Water recycling presumes HTC occurs on a dynamic (flowing) mode, a set-up largely unstudied compared to static (batch) conditions. Finally, cost-benefit and life-cycle 
assessments based on local conditions and feedstocks are missing which are essential before scaling-up of the process. Towards this purpose, the ability of ANNs to predict HHVs of hydrochars regardless of the original biomass used, was demonstrated. Of all the input parameters tested (C, H, O content, HTC temperature and time), $\mathrm{C}$ content was found to be the most closely correlated variable to $\mathrm{HHV}$, whereas HTC time showed the least correlation of all. Of the four ANNs developed, $\mathrm{ANN}_{3}$ (based on $\mathrm{C}, \mathrm{H}, \mathrm{O}$ and temperature as inputs) exhibited the optimum performance, however, $\mathrm{ANN}_{1}$ (based only on $\mathrm{C}$ content of hydrochars) had a satisfactory performance. Practically, this means that only one laboratory analysis is required for the accurate estimation of the HHV of hydrochars, thus largely reducing the cost and time of research work. In combination with the reverse $\mathrm{ANN}$ model $\left(\mathrm{ANN}_{4}\right)$, researchers will be able to focus on biomasses with a minimum $C$ content for the production of hydrochar, thus adjusting accordingly their HTC temperature (by far the most important process variable). Biomasses with lower initial C content would require higher HTC temperature to improve their fuel properties and resulting in a more energy-demanding process. On the contrary, biomasses with higher initial $\mathrm{C}$ content would require milder HTC conditions to achieve hydrochars with the required HHV, thus reducing the cost of the process.

Supplementary Materials: The following are available online at http://www.mdpi.com/1996-1073/13/17/4572/s1, Figure S1: Architecture of a feedforward MLP ANN with one input, one hidden and one output layer., Figure S2: MRE (\%) as a function of the number of neurons in the hidden layer.

Author Contributions: Conceptualization, I.O.V., and D.K.; methodology, T.N.K., C.D.N.; software, I.O.V., T.N.K., and C.D.N.; validation, I.O.V., T.N.K., and C.D.N.; formal analysis, I.O.V., D.K.; investigation, T.K.T., T.T., R.K., A.K.; resources, I.O.V., D.K.; data curation, T.K.T., T.T., R.K., A.K.; writing—original draft preparation, D.K.; writing-review and editing, I.O.V., D.K.; visualization, T.N.K., C.D.N.; supervision, D.K.; project administration, D.K.; All authors have read and agreed to the published version of the manuscript.

Funding: This research received no external funding.

Conflicts of Interest: The authors declare no conflict of interest.

\section{References}

1. Jiménez-Carmona, M.M.; Luque de Castro, M.D. Isolation of eucalyptus essential oil for GC-MS analysis by extraction with subcritical water. Chromatographia 1999, 50, 578-582. [CrossRef]

2. Jiménez-Carmona, M.M.; Ubera, J.L.; Luque De Castro, M.D. Comparison of continuous subcritical water extraction and hydrodistillation of marjoram essential oil. J. Chromatogr. A 1999, 855, 625-632. [CrossRef]

3. Rovio, S.; Hartonen, K.; Holm, Y.; Hiltunen, R.; Riekkola, M.L. Extraction of clove using pressurized hot water. Flavour Fragr. J. 1999, 14, 399-404. [CrossRef]

4. Yang, Y.; Jones, A.D.; Eaton, C.D. Retention behavior of phenols, anilines, and alkylbenzenes in liquid chromatographic separations using subcritical water as the mobile phase. Anal. Chem. 1999, 71, 3808-3813. [CrossRef]

5. Yang, Y.; Li, B. Subcritical water extraction coupled to high-performance liquid chromatography. Anal. Chem. 1999, 71, 1491-1495. [CrossRef]

6. Hawthorne, S.B.; Lagadec, A.J.M.; Kalderis, D.; Lilke, A.V.; Miller, D.J. Pilot-scale destruction of TNT, RDX, and HMX on contaminated soils using subcritical water. Environ. Sci. Technol. 2000, 34, 3224-3228. [CrossRef]

7. Kubatova, A.; Lagadec, A.J.M.; Hawthorne, S.B. Dechlorination of lindane, dieldrin, tetrachloroethane, trichloroethene and PVC in Subcritical Water. Environ. Sci. Technol. 2002, 36, 1337-1343. [CrossRef]

8. Daskalaki, V.M.; Timotheatou, E.S.; Katsaounis, A.; Kalderis, D. Degradation of Reactive Red 120 using hydrogen peroxide in subcritical water. Desalination 2011, 274, 200-205. [CrossRef]

9. Kirmizakis, P.; Tsamoutsoglou, C.; Kayan, B.; Kalderis, D. Subcritical water treatment of landfill leachate: Application of response surface methodology. J. Environ. Manag. 2014, 146, 9-15. [CrossRef]

10. Skubiszewska-Zi, J.; Charmas, B.; Leboda, R.; Staszczuk, P.; Kowalczyk, P.; Oleszczuk, P. Effect of hydrothermal modification on the porous structure and thermal properties of carbon-silica adsorbents (carbosils). Mater. Chem. Phys. 2003, 78, 486-494. [CrossRef]

11. Yu, S.H.; Cui, X.; Li, L.; Li, K.; Yu, B.; Antonietti, M.; Cölfen, H. From starch to metal/carbon hybrid nanostructures: Hydrothermal metal-catalyzed carbonization. Adv. Mater. 2004, 16, 1636-1640. [CrossRef] 
12. Sarkar, N.B.; Sarkar, P.; Choudhury, A. Effect of hydrothermal treatment of coal on the oxidation susceptibility and electrical resistivity of HTT coke. Fuel Process. Technol. 2005, 86, 487-497. [CrossRef]

13. Funke, A.; Ziegler, F. Hydrothermal carbonization of biomass: A summary and discussion of chemical mechanisms for process engineering. Biofuel Bioprod. Biorefin. 2010, 4, 160-177. [CrossRef]

14. Libra, J.A.; Ro, K.S.; Kammann, C.; Funke, A.; Berge, N.D.; Neubauer, Y.; Titirici, M.-M.; Fühner, C.; Bens, O.; Kern, J.; et al. Hydrothermal carbonization of biomass residuals: A comparative review of the chemistry, processes and applications of wet and dry pyrolysis. Biofuels 2011, 2, 71-106. [CrossRef]

15. Heidari, M.; Dutta, A.; Acharya, B.; Mahmud, S. A review of the current knowledge and challenges of hydrothermal carbonization for biomass conversion. J. Energy Inst. 2019, 92, 1779-1799. [CrossRef]

16. Wang, T.; Zhai, Y.; Zhu, Y.; Li, C.; Zeng, G. A review of the hydrothermal carbonization of biomass waste for hydrochar formation: Process conditions, fundamentals, and physicochemical properties. Renew. Sustain. Energy Rev. 2018, 90, 223-247. [CrossRef]

17. McGaughy, K.; Toufiq Reza, M. Hydrothermal carbonization of food waste: Simplified process simulation model based on experimental results. Biomass Convers. Biorefin. 2018, 8, 283-292. [CrossRef]

18. Gallifuoco, A. A new approach to kinetic modeling of biomass hydrothermal carbonization. ACS Sustain. Chem. Eng. 2019, 7, 13073-13080. [CrossRef]

19. Conag, A.T.; Villahermosa, J.E.R.; Cabatingan, L.K.; Go, A.W. Predictive HHV model for raw and torrefied sugarcane residues. Waste Biomass Valorization 2019, 10, 1929-1943. [CrossRef]

20. Vallejo, F.; Díaz-Robles, L.A.; Vega, R.; Cubillos, F. A novel approach for prediction of mass yield and higher calorific value of hydrothermal carbonization by a robust multilinear model and regression trees. J. Energy Inst. 2020, 93, 1755-1762. [CrossRef]

21. Akdeniz, F.; Biçil, M.; Karadede, Y.; Özbek, F.E.; Özdemir, G. Application of real valued genetic algorithm on prediction of higher heating values of various lignocellulosic materials using lignin and extractive contents. Energy 2018, 160, 1047-1054. [CrossRef]

22. Kapetanakis, T.N.; Vardiambasis, I.O.; Ioannidou, M.P.; Maras, A. Neural network modeling for the solution of the inverse loop antenna radiation problem. IEEE Trans. Antennas Propag. 2018, 66, 6283-6290. [CrossRef]

23. Sergaki, E.; Spiliotis, G.; Vardiambasis, I.O.; Kapetanakis, T.; Krasoudakis, A.; Giakos, G.C.; Zervakis, M.; Polydorou, A. Application of ANN and ANFIS for Detection of Brain Tumors in MRIs by Using DWT and GLCM Texture Analysis. In Proceedings of the IST 2018-International Conference on Imaging Systems and Techniques, Krakow, Poland, 16-18 October 2018; pp. 1-6.

24. Bhange, V.P.; Bhivgade, U.V.; Vaidya, A.N. Artificial Neural Network Modeling in Pretreatment of Garden Biomass for Lignocellulose Degradation. Waste Biomass Valorization 2019, 10, 1571-1583. [CrossRef]

25. Baruah, D.; Baruah, D.C.; Hazarika, M.K. Artificial neural network based modeling of biomass gasification in fixed bed downdraft gasifiers. Biomass Bioenergy 2017, 98, 264-271. [CrossRef]

26. Nasrudin, N.A.; Jewaratnam, J.; Hossain, M.A.; Ganeson, P.B. Performance comparison of feedforward neural network training algorithms in modelling microwave pyrolysis of oil palm fibre for hydrogen and biochar production. Asia-Pac. J. Chem. Eng. 2020, 15. [CrossRef]

27. Chen, C.; Liu, G.; An, Q.; Lin, L.; Shang, Y.; Wan, C. From wasted sludge to valuable biochar by low temperature hydrothermal carbonization treatment: Insight into the surface characteristics. J. Clean. Prod. 2020, 263, 121600. [CrossRef]

28. Zheng, X.; Jiang, Z.; Ying, Z.; Song, J.; Chen, W.; Wang, B. Role of feedstock properties and hydrothermal carbonization conditions on fuel properties of sewage sludge-derived hydrochar using multiple linear regression technique. Fuel 2020, 271, 117609. [CrossRef]

29. Chen, C.; Ibekwe-Sanjuan, F.; Hou, J. The Structure and Dynamics of Co-Citation Clusters: A Multiple-Perspective the Structure and Dynamics of Co-Citation Clusters: A Multiple-Perspective Co-Citation Analysis. J. Am. Soc. Inf. Sci. Technol. 2010, 61, 1386-1409. [CrossRef]

30. Chen, C. CiteSpace II: Detecting and visualizing emerging trends and transient patterns in scientific literature. J. Assoc. Inf. Sci. Technol. 2006, 57, 359-377. [CrossRef]

31. Fang, Y.; Yin, J.; Wu, B. Climate change and tourism: A scientometric analysis using CiteSpace. J. Sustain. Tour. 2018, 26, 108-126. [CrossRef]

32. Wu, P.; Wang, Z.; Wang, H.; Bolan, N.S.; Wang, Y.; Chen, W. Visualizing the emerging trends of biochar research and applications in 2019: A scientometric analysis and review. Biochar 2020, 2, 135-150. [CrossRef] 
33. Teoh, S.K.; Li, L.Y. Feasibility of alternative sewage sludge treatment methods from a lifecycle assessment (LCA) perspective. J. Clean. Prod. 2020, 247, 119495. [CrossRef]

34. Cieślik, B.M.; Namieśnik, J.; Konieczka, P. Review of sewage sludge management: Standards, regulations and analytical methods. J. Clean. Prod. 2015, 90, 1-15. [CrossRef]

35. Chang, Z.; Long, G.; Zhou, J.L.; Ma, C. Valorization of sewage sludge in the fabrication of construction and building materials: A review. Resour. Conserv. Recycl. 2020, 154, 104606. [CrossRef]

36. Zhao, P.; Shen, Y.; Ge, S.; Yoshikawa, K. Energy recycling from sewage sludge by producing solid biofuel with hydrothermal carbonization. Energy Convers. Manag. 2014, 78, 815-821. [CrossRef]

37. Kim, D.; Lee, K.; Park, K.Y. Hydrothermal carbonization of anaerobically digested sludge for solid fuel production and energy recovery. Fuel 2014, 130, 120-125. [CrossRef]

38. Parshetti, G.K.; Liu, Z.; Jain, A.; Srinivasan, M.P.; Balasubramanian, R. Hydrothermal carbonization of sewage sludge for energy production with coal. Fuel 2013, 111, 201-210. [CrossRef]

39. Gai, C.; Chen, M.; Liu, T.; Peng, N.; Liu, Z. Gasification characteristics of hydrochar and pyrochar derived from sewage sludge. Energy 2016, 113, 957-965. [CrossRef]

40. Danso-Boateng, E.; Shama, G.; Wheatley, A.D.; Martin, S.J.; Holdich, R.G. Hydrothermal carbonisation of sewage sludge: Effect of process conditions on product characteristics and methane production. Bioresour. Technol. 2015, 177, 318-327. [CrossRef]

41. Silva, R.D.V.K.; Lei, Z.; Shimizu, K.; Zhang, Z. Hydrothermal treatment of sewage sludge to produce solid biofuel: Focus on fuel characteristics. Bioresour. Technol. Rep. 2020, 11, 100453. [CrossRef]

42. Mäkelä, M.; Fullana, A.; Yoshikawa, K. Ash behavior during hydrothermal treatment for solid fuel applications. Part 1: Overview of different feedstock. Energy Convers. Manag. 2016, 121, 402-408. [CrossRef]

43. Mäkelä, M.; Yoshikawa, K. Ash behavior during hydrothermal treatment for solid fuel applications. Part 2: Effects of treatment conditions on industrial waste biomass. Energy Convers. Manag. 2016, 121, 409-414. [CrossRef]

44. Smith, A.M.; Singh, S.; Ross, A.B. Fate of inorganic material during hydrothermal carbonisation of biomass: Influence of feedstock on combustion behaviour of hydrochar. Fuel 2016, 169, 135-145. [CrossRef]

45. Parmar, K.R.; Ross, A.B. Integration of hydrothermal carbonisation with anaerobic digestion; Opportunities for valorisation of digestate. Energies 2019, 12, 1586. [CrossRef]

46. Wang, L.; Chang, Y.; Li, A. Hydrothermal carbonization for energy-efficient processing of sewage sludge: A review. Renew. Sustain. Energy Rev. 2019, 108, 423-440. [CrossRef]

47. Tasca, A.L.; Puccini, M.; Gori, R.; Corsi, I.; Galletti, A.M.R.; Vitolo, S. Hydrothermal carbonization of sewage sludge: A critical analysis of process severity, hydrochar properties and environmental implications. Waste Manag. 2019, 93, 1-13. [CrossRef]

48. Niinipuu, M.; Latham, K.G.; Boily, J.F.; Bergknut, M.; Jansson, S. The impact of hydrothermal carbonization on the surface functionalities of wet waste materials for water treatment applications. Environ. Sci. Pollut. Res. 2020, 27, 24369-24379. [CrossRef]

49. Ma, J.; Chen, M.; Yang, T.; Liu, Z.; Jiao, W.; Li, D.; Gai, C. Gasification performance of the hydrochar derived from co-hydrothermal carbonization of sewage sludge and sawdust. Energy 2019, 173, 732-739. [CrossRef]

50. Ma, J.; Luo, H.; Li, Y.; Liu, Z.; Li, D.; Gai, C.; Jiao, W. Pyrolysis kinetics and thermodynamic parameters of the hydrochars derived from co-hydrothermal carbonization of sawdust and sewage sludge using thermogravimetric analysis. Bioresour. Technol. 2019, 282, 133-141. [CrossRef]

51. Song, Y.; Zhan, H.; Zhuang, X.; Yin, X.; Wu, C. Synergistic characteristics and capabilities of co-hydrothermal carbonization of sewage sludge/lignite mixtures. Energy Fuels 2019, 33, 8735-8745. [CrossRef]

52. Wang, L.; Chang, Y.; Zhang, X.; Yang, F.; Li, Y.; Yang, X.; Dong, S. Hydrothermal co-carbonization of sewage sludge and high concentration phenolic wastewater for production of solid biofuel with increased calorific value. J. Clean. Prod. 2020, 255, 120317. [CrossRef]

53. Lee, J.; Sohn, D.; Lee, K.; Park, K.Y. Solid fuel production through hydrothermal carbonization of sewage sludge and microalgae Chlorella sp. from wastewater treatment plant. Chemosphere 2019, 230, 157-163. [CrossRef] [PubMed]

54. Xu, Z.X.; Song, H.; Zhang, S.; Tong, S.Q.; He, Z.X.; Wang, Q.; Li, B.; Hu, X. Co-hydrothermal carbonization of digested sewage sludge and cow dung biogas residue: Investigation of the reaction characteristics. Energy 2019, 187, 115972. [CrossRef] 
55. Zheng, C.; Ma, X.; Yao, Z.; Chen, X. The properties and combustion behaviors of hydrochars derived from co-hydrothermal carbonization of sewage sludge and food waste. Bioresour. Technol. 2019, 285, 121347. [CrossRef]

56. He, C.; Zhang, Z.; Ge, C.; Liu, W.; Tang, Y.; Zhuang, X.; Qiu, R. Synergistic effect of hydrothermal co-carbonization of sewage sludge with fruit and agricultural wastes on hydrochar fuel quality and combustion behavior. Waste Manag. 2019, 100, 171-181. [CrossRef]

57. Heilmann, S.M.; Molde, J.S.; Timler, J.G.; Wood, B.M.; Mikula, A.L.; Vozhdayev, G.V.; Colosky, E.C.; Spokas, K.A.; Valentas, K.J. Phosphorus reclamation through hydrothermal carbonization of animal manures. Environ. Sci. Technol. 2014, 48, 10323-10329. [CrossRef]

58. Ovsyannikova, E.; Arauzo, P.J.; Becker, G.; Kruse, A. Experimental and thermodynamic studies of phosphate behavior during the hydrothermal carbonization of sewage sludge. Sci. Total Environ. 2019, 692, 147-156. [CrossRef]

59. Becker, G.C.; Wüst, D.; Köhler, H.; Lautenbach, A.; Kruse, A. Novel approach of phosphate-reclamation as struvite from sewage sludge by utilising hydrothermal carbonization. J. Environ. Manag. 2019, 238, 119-125. [CrossRef]

60. Cui, X.; Lu, M.; Khan, M.B.; Lai, C.; Yang, X.; He, Z.; Chen, G.; Yan, B. Hydrothermal carbonization of different wetland biomass wastes: Phosphorus reclamation and hydrochar production. Waste Manag. 2020, 102, 106-113. [CrossRef]

61. Aragón-Briceño, C.I.; Grasham, O.; Ross, A.B.; Dupont, V.; Camargo-Valero, M.A. Hydrothermal carbonization of sewage digestate at wastewater treatment works: Influence of solid loading on characteristics of hydrochar, process water and plant energetics. Renew. Energy 2020, 157, 959-973. [CrossRef]

62. Marin-Batista, J.D.; Mohedano, A.F.; Rodríguez, J.J.; de la Rubia, M.A. Energy and phosphorous recovery through hydrothermal carbonization of digested sewage sludge. Waste Manag. 2020, 105, 566-574. [CrossRef]

63. Song, E.; Park, S.; Kim, H. Upgrading hydrothermal carbonization (HTC) hydrochar from sewage sludge. Energies 2019, 12, 2383. [CrossRef]

64. Xu, Z.X.; Song, H.; Li, P.J.; He, Z.X.; Wang, Q.; Wang, K.; Duan, P.G. Hydrothermal carbonization of sewage sludge: Effect of aqueous phase recycling. Chem. Eng. J. 2020, 387, 123410. [CrossRef]

65. Wang, R.; Wang, C.; Zhao, Z.; Jia, J.; Jin, Q. Energy recovery from high-ash municipal sewage sludge by hydrothermal carbonization: Fuel characteristics of biosolid products. Energy 2019, 186, 115848. [CrossRef]

66. Hansen, L.J.; Fendt, S.; Spliethoff, H. Impact of hydrothermal carbonization on combustion properties of residual biomass. Biomass Convers. Biorefin. 2020. [CrossRef]

67. Xu, Z.X.; Song, H.; Li, P.J.; Zhu, X.; Zhang, S.; Wang, Q.; Duan, P.G.; Hu, X. A new method for removal of nitrogen in sewage sludge-derived hydrochar with hydrotalcite as the catalyst. J. Hazard. Mater. 2020, 398, 122833. [CrossRef]

68. Lin, Y.; Ma, X.; Peng, X.; Yu, Z. Hydrothermal carbonization of typical components of municipal solid waste for deriving hydrochars and their combustion behavior. Bioresour. Technol. 2017, 243, 539-547. [CrossRef]

69. Gallifuoco, A.; Taglieri, L.; Scimia, F.; Papa, A.A.; Di Giacomo, G. Hydrothermal carbonization of Biomass: New experimental procedures for improving the industrial Processes. Bioresour. Technol. 2017, 244, 160-165. [CrossRef]

70. Wang, T.; Zhai, Y.; Li, H.; Zhu, Y.; Li, S.; Peng, C.; Wang, B.; Wang, Z.; Xi, Y.; Wang, S.; et al. Co-hydrothermal carbonization of food waste-woody biomass blend towards biofuel pellets production. Bioresour. Technol. 2018, 267, 371-377. [CrossRef]

71. Saqib, N.U.; Sharma, H.B.; Baroutian, S.; Dubey, B.; Sarmah, A.K. Valorisation of food waste via hydrothermal carbonisation and techno-economic feasibility assessment. Sci. Total Environ. 2019, 690, 261-276. [CrossRef]

72. Zhao, K.; Li, Y.; Zhou, Y.; Guo, W.; Jiang, H.; Xu, Q. Characterization of hydrothermal carbonization products (hydrochars and spent liquor) and their biomethane production performance. Bioresour. Technol. 2018, 267, 9-16. [CrossRef] [PubMed]

73. Saqib, N.U.; Baroutian, S.; Sarmah, A.K. Physicochemical, structural and combustion characterization of food waste hydrochar obtained by hydrothermal carbonization. Bioresour. Technol. 2018, 266, 357-363. [CrossRef] [PubMed]

74. Tradler, S.B.; Mayr, S.; Himmelsbach, M.; Priewasser, R.; Baumgartner, W.; Stadler, A.T. Hydrothermal carbonization as an all-inclusive process for food-waste conversion. Bioresour. Technol. Rep. 2018, 2, 77-83. [CrossRef] 
75. Li, Y.; Liu, H.; Xiao, K.; Jin, M.; Xiao, H.; Yao, H. Combustion and Pyrolysis Characteristics of Hydrochar Prepared by Hydrothermal Carbonization of Typical Food Waste: Influence of Carbohydrates, Proteins, and Lipids. Energy Fuels 2020, 34, 430-439. [CrossRef]

76. Akarsu, K.; Duman, G.; Yilmazer, A.; Keskin, T.; Azbar, N.; Yanik, J. Sustainable valorization of food wastes into solid fuel by hydrothermal carbonization. Bioresour. Technol. 2019, 292, 121959. [CrossRef]

77. Atiqah Nasir, N.; Davies, G.; McGregor, J. Tailoring product characteristics in the carbonisation of brewers' spent grain through solvent selection. Food Bioprod. Process. 2020, 120, 41-47. [CrossRef]

78. Santos Santana, M.; Pereira Alves, R.; da Silva Borges, W.M.; Francisquini, E.; Guerreiro, M.C. Hydrochar production from defective coffee beans by hydrothermal carbonization. Bioresour. Technol. 2020, 300, 122653. [CrossRef]

79. Zhang, B.; Heidari, M.; Regmi, B.; Salaudeen, S.; Arku, P.; Thimmannagari, M.; Dutta, A. Hydrothermal carbonization of fruit wastes: A promising technique for generating hydrochar. Energies 2018, 11, 2022. [CrossRef]

80. Xiao, K.; Liu, H.; Li, Y.; Yi, L.; Zhang, X.; Hu, H.; Yao, H. Correlations between hydrochar properties and chemical constitution of orange peel waste during hydrothermal carbonization. Bioresour. Technol. 2018, 265, 432-436. [CrossRef]

81. Tamelová, B.; Malat'ák, J.; Velebil, J. Hydrothermal carbonization and torrefaction of cabbage waste. Agron. Res. 2019, 17, 862-871.

82. Ul Saqib, N.; Sarmah, A.K.; Baroutian, S. Effect of temperature on the fuel properties of food waste and coal blend treated under co-hydrothermal carbonization. Waste Manag. 2019, 89, 236-246. [CrossRef] [PubMed]

83. Mazumder, S.; Saha, P.; Reza, M.T. Co-hydrothermal carbonization of coal waste and food waste: Fuel characteristics. Biomass Convers. Biorefin. 2020. [CrossRef]

84. Mazumder, S.; Saha, P.; McGaughy, K.; Saba, A.; Reza, M.T. Technoeconomic analysis of co-hydrothermal carbonization of coal waste and food waste. Biomass Convers. Biorefin. 2020. [CrossRef]

85. Gupta, D.; Mahajani, S.M.; Garg, A. Effect of hydrothermal carbonization as pretreatment on energy recovery from food and paper wastes. Bioresour. Technol. 2019, 285, 121329. [CrossRef] [PubMed]

86. Kapetanakis, T.N.; Vardiambasis, I.O.; Lourakis, E.I.; Maras, A. Applying neuro-fuzzy soft computing techniques to the circular loop antenna radiation problem. IEEE Antennas Wirel. Propag. Lett. 2018, 17, 1673-1676. [CrossRef]

87. Liodakis, G.; Arvanitis, D.; Vardiambasis, I.O. Neural network-based digital receiver for radio communications. WSEAS Trans. Syst. 2004, 3, 3308-3313. 